\title{
THE NEW YORK PLAN: A FREE CHOICE MODIFICATION
}

\author{
GUIDO CALABRESI*
}

The New York plan is, in my opinion, the best first party systen that has yet been proposed. It has, to be sure, some weaknesses. For instance, a complete system of automobile accident law must provide for the imposition of noninsurable tort fines, preferably income-related, to supplement the enterprise or market deterrence that can be achieved through an intelligent allocation of accident costs. ${ }^{1}$ The New York plan does not provide for such a system of tort fines. ${ }^{2}$ It is not my purpose, however, to devote this article to a consideration of possible omissions of this kind. Nor do I propose to discuss those characteristics of the plan that I think are especially desirable, for example, that it, unlike the Keeton-O'Connell plan, is not subject to early obsolescence because of inflation. ${ }^{3}$ Rather, I intend to discuss the two principal criticisms that have been made of the New York plan, and to suggest a free choice modification which, if worked out in detail, might meet these objections. It is assumed, of course, that the objections that have been made to the plan are motivated by good faith and not by an interest in retaining the status quo.

The first asserted objection to the New York proposal is that the public does not want a nonfault insurance plan that does not provide for compulsory compensation for pain and suffering; in short, despite all its deficiencies, people prefer the present tort liability system. The second asserted objection is that the administrative cost savings envisaged under the New York plan are, as a practical matter, illusory; they would be more than overcome by increases in the number of serious accidents which opponents of the plan assert would follow its adoption. This latter objection implies that the advocates of a nonfault plan are selling a pig in a poke which, once bought, cannot be returned.

Both of these objections would be overcome if it were possible for individuals to choose either to remain under the existing tort liability system or to opt for the nonfault coverage proposed by the New York plan. In either

* John Thomas Smith Professor of Law, Yale University. B.S., Yale, 1953, LL.B., 1958; M.A., Oxford, 1959; M.A., Yale, 1962. After this article was written, I had occasion to read Professors Keeton and O'Connell's contribution to this symposium. The similarities between our approaches are striking. It is encouraging that we independently reached such closely related conclusions.

1. For a general discussion of the relationship between market deterrence and fines, as well as how each of these is related to other goals of accident law, see G. CALABRESI, The Costs of Accidents: A Legat and Economic Analysis (1970).

2. The explanation for this omission may well be that the plan was formulated by the New York Insurance Department and income-related tort fines are far afield from insurance regulation.

3. I am referring, of course, to the fact that the New York plan covers full economic loss; the coverage is not limited to a dollar maximum which all too soon becomes totally different, in real terms, from that intended. 
case, the individual would bear the costs of the plan he chose. I believe that a system can be created that 'would allow this freedom of choice. Such a system would entail some administrative costs, and, in the system sketched out below, these costs would be disproportionately borne by those who chose the new first party plan. But, this additional burden may be appropriate, at least until such time as the reform has demonstrated its merit.4

The proposed free choice system would require all car owners to choose to be insured under either a first party system or a slightly modified version of the tort liability system. An automobile owner who opted for the tort liability system would retain his rights to recover under existing rules of law and would be liable under those same rules for injuries caused by him. This right to recovery and these liabilities would continue to be governed by the familiar tort rules of negligence and contributory negligence; the collateral benefits rule would apply; and damages for pain and suffering would continue to be awarded or assessed. The one suggested change would be to raise the level of compulsory third party insurance to as near to total conceivable coverage as possible; individuals would be allowed, however, to opt out or to obtain a deductible provision upon a showing of financial responsibility. ${ }^{5}$

The rights and liabilities of a car owner who chose a first party plan would be essentially those described in the New York plan. He would recover his full economic loss from his first party insurer, but he would not recover for pain and suffering or for certain kinds of property damage unless he elected to purchase coverage beyond the minimum required. ${ }^{3} \mathrm{He}$ would also not, however, be liable to third parties with the possible exception of passengers and pedestrians.

A problem would arise upon the occurrence of an accident that involved some parties who had chosen the present system and some who had chosen

4. I am not suggesting that either of the objections made to the New York plan are valid. In fact, I would guess them both to be nonsense. Nevertheless, it may be appropriate to test out such a guess and to put the burden of proof on those who, like myself, believe in change.

5. In this country at least, unlimited third party automobile liability insurance apparently is not easily available. Short of such unlimited coverage, compulsory insurance (or proof of financial responsibility) ought to be high enough so that virtually all accident costs would in fact be borne by those who are held liable. Anything less would understate the true costs of the tort liability system. To the extent that a driver could avoid paying for losses he caused by being underinsured and judgment-proof, his choice for the tort liability system would be subsidized by those who were unlucky enough to be seriously injured by him. That result cannot be a valid basis for choosing existing law.

6. I think a first party plan should provide not only optional, scheduled insurance for dignitary losses (so much for an arm, so much for a leg), but also optional, scheduled insurance for pure pain and suffering. But to schedule pain and suffering as such is probably impossible. An adequate way of dealing with the matter is to allow people who opt for first party insurance to insure against pain and suffering, which would be defined as a set percentage of, say, medical bills. An insurance company could offer various options at various prices, e.g., $50 \%, 100 \%$ or $200 \%$, of medical bills as additional pain and suffering coverage. In effect, this option would allow people to value their own propensity for pain and suffering, analogously to what they do today when they buy life insurance. Cf. American Insurance Association, Report of Spectal Committee to Study AND Evaluate the Keeton-O'Connelt Basic Protection Plan and Autoniodile Accident Reparations (1968). 
the New York plan. Before dealing with that problem, however, it may be well to describe what would happen in the unlikely event that all accidents involved only those who had chosen the same accident law system. Under this heroic assumption, the insurance costs under each plan would reflect a combination of the administrative and accident costs of that plan. If, as the proponents of first party plans claim, administrative costs are much reduced and accident costs are either left unchanged or reduced by a first party plan, then premiums under the first party plan would be much less than those under the tort liability system. If, instead, the proponents of the tort liability system are correct in their contention that the administrative savings of first party plans would be either illusory or devoured by an increase in accident costs, then premiums under the first party plan would be higher than those under the tort liability system. In either event, individuals would be free to choose which protection they prefer; indeed, some might rationally choose the higher priced plan because they prefer the protection it affords.

This freedom of choice is not available under the present system; nor would it be under the New York plan as currently proposed. At present, a car owner can purchase full economic coverage from a first party insurer; under current law, however, he must also pay for third party insurance and receive, for a price, what he may not desire: the right to sue at common law for damages including pain and suffering and the right to double recovery entailed by the collateral benefits rule. Similarly, under the New York proposal, the car owner who did not want full economic coverage, but who instead wanted to gamble on being doubly compensated for losses from collateral sources and under the fault principle could not buy the coverage he desired. The plan here suggested would test in practical operation what coverage people in fact desire. This test would be conducted in the light of the actual costs of the two proposed systems of coverage-costs measured in terms of the number and severity of accidents and the extent of administrative expenses.

Not all accidents, of course, would involve people who have chosen the same plan; many accidents would be "mixed." Although provisions for dealing with "mixed" accidents complicate this free choice plan, they do not present insurmountable obstacles. Let us assume that D. R. I. Atla (who chose the tort liability system) was injured in an accident negligently caused by Stewart O'Keeton (who opted for the first party system). Since O'Keeton would not be liable, how would Atla recover? The free choice scheme would require the equivalent of an uninsured motorist pool that would serve as the subrogated defendant against which Atla would have recourse under tort law. Where would the pool obtain the money to pay for such suits? Presumably there would also be accidents in which D. R. I. Atla negligently injured Stewart O'Keeton. In such cases, the pool, as the subrogated plaintiff, would recover from Atla all damages available under existing tort law.

This leaves two questions unanswered. First, who would pay the adminis- 
trative costs of the fund? And second, what would happen if the amount collected by the fund as subrogated plaintiff were less (or more) than the amount it had to pay as subrogated defendant? With regard to the first question, the administrative costs would be charged to all third and first party insurers in the state, in proportion to the amounts of insurance each had sold. In effect, this procedure would allocate the administrative costs of a free choice system among all persons insured under both systems. Although this procedure appears on its face to be fair, it would actually favor those who elected to remain under the tort liability system, because the administrative costs incurred by the fund would arise from suits under tort law. Thus, those who opted for the new approach would still be burdened with some of the costs of the fault liability system. The same complaint could not be made by those who opted for the existing tort liability system since they would simply be paying their share of the administrative costs of the system they had chosen. But, I am not unduly troubled by this extra burden on those who would choose the new first party system; as innovators, they might be justifiably called upon to bear some burdens, at least until the change was shown to be desirable.

A more complex problem may arise, however, since the revenuses of the fund need not equal its expenditures. If car owners who chose first party plans had more accidents in which they were at fault than those who chose the fault liability system, the fund would lose more in its role as a defendant than it would win as plaintiff, thereby creating an excess of expenditures over receipts. Conversely, if car owners who chose first party plans had fewer accidents in which they were at fault than those who remained under the tort liability system, the fund would receive more damage awards as plaintiffs than it expended as defendants. These problems, which essentially go to the relative general deterrence effect of two systems, might be heightened by a kind of selfselection among people choosing between the two plans.7

Again, however, these problems are not insurmountable. A deficit in the fund would indicate that premiums for first party plan coverage were too low in that they failed to reflect the excess costs of accidents, caused by those insured under such coverage, to those who remained under the tort liability system. Conversely, a surplus in the fund would indicate that first party premiums were too high and failed to reflect the fact that first party car owners were safer drivers or operated safer cars. Any resulting deficit, therefore, should be raised by charging all first party insurers an appropriate share based on the amount of insurance each sells in the state; this assessment would in turn cause insurers to increase first party premiums. If a surplus resulted, the fund would inake payments to the first party insurers, who in turn would reduce first party premiums in the following year. In either event,

7. Cf. G. Calabresi, The Costs of Accidents: A Legal and Economic Analysis, supra note 1 , at 7-10. 
the full cost of mixed accidents would be properly allocated. ${ }^{8}$ This statement, however, requires a caveat. Here too, those who opted for first party insurance coverage would be at a disadavantage. For the determination of who ought to bear the costs of mixed accidents would, in effect, be made by the legal norms they had rejected. One could, of course, deal with mixed accidents in a way that was less biased toward the status quo. As stated above, however, for the purposes of this article, I remain willing to allocate all the doubtful burdens to the innovators.

Before noting some remaining issues in regard to the free choice system, it may be well to re-emphasize what could be achieved under a free choice plan. People could decide whether they preferred existing tort liability insurance or first party insurance. A free choice plan would allow car owners to choose with knowledge of the real administrative and accident costs of each system; that is, car owners would be required to choose between insurance prices that would refiect both the accident cost avoidance effect of each system and the administrative costs needed to buy that accident cost avoidance. In short, the free choice plan would let consumer sovereignty prevail.

Several issues remain, which I do not propose to treat fully in this article. The first problem relates to the treatment of pedestrian and passenger victims. $\mathrm{My}$ inclination is to deal with them under the following rules. (1) If the pedestrian or passenger is a car owner, he will have opted either for the New York plan or for the tort liability plan. That choice would determine his rights and liabilities even when his injury occurred while he was a passenger or pedestrian.9 (2) If the pedestrian or passenger is not a car owner but is a member of a household in which there is one registered car owner, the rights and liabilities of the pedestrian or passenger would be determined by the plan chosen by the registered owner. (3) If there is more than one registered car owner in the household, rights and liabilities would be provisionally determined by the plan chosen by the "head of the houseliold." The passenger or pedestrian would however, be allowed to make a different choice prior to an accident by filing notice witli an appropriate state department that he chooses to adopt for himself the type of coverage which another car owner in the household has

8. The state insurance department would have to establish a procedure by which these charges or refunds to first party sellers would be speedily reflected in the succeeding year's premiums. If insurance companies are to sell first party insurance, they must be allowed to pass on quickly any excess charges to the insured. Similarly, if motorists are to be given a meaningful free choice, any surplus must also be quickly reflected in lower charges. Like the manner in which the fund could be guaranteed until the system is fully working, these details must be worked out, but they present no theoretical difficulties.

9. That is, he would be dealt with precisely as the New York plan, as currently presented, deals with injured pedestrians or passengers. If the car causing the injury, however, is owned by someone who opted for tort liability insurance, the passenger or pedestrian could either be given recovery from his own first party insurer or from the pool. Each approach has advantages, and either is acceptable so long as only one is allowed. In either case the pool would be a subrogated plaintiff. 
elected. ${ }^{10}$ (4) if no one in the household is a car owner, either system could be assumed to rule so long as the individuals involved were allowed to opt for the opposite system by filing an appropriate notice. ${ }^{11}$ This outline obviously is not meant to exhaust the problems of pedestrians and passengers, but simply to suggest that they too can be dealt with effectively.

The second remaining issue in regard to a free choice system is that of tort fines. Again, the question is too broad to deal with fully here. Nothing in the proposed system, however, precludes the institution of uninsurable tort fines, whether or not income related, only for those who opted for the New York plan or only for those who chose the tort liability'system or for both. Whether tort fines would be added to either plan might depend upon the effect each plan had on accident costs and therefore on premiums. For example, if too many first party insureds caused accidents, those who opted for such a plan might advocate the imposition of tort fines in order to reduce their premiums. The same result might obtain for those who chose the tort liability system if they determined that existing law resulted in excessive accident costs and premiums.

The point of this example is general and goes well beyond the tort fine issue. Allowing a choice between the New York plan and the existing system does not imply that either is the best approach possible; indeed, that possible improvements can be made in both is obvious. The two plans represent, however, important alternative approaches, and, if free choice between the two were allowed, further improvements in each system would not be excluded but, rather, would be encouraged. As each plan competed with the other for customers, a great incentive toward improving both would automatically arise.

This discussion raises a final question: is it worth having a double system, and if it is, why not provide still more options? The simple answer to the first part of this question is, let us see. The arguments in favor of some kind of first party plan are strong. After all, a frequent defense made of the present tort liability system is premised on the fact that many people buy first party coverage to supplement recoveries under the fault system, and, therefore, are not left penniless in nonfault accident situations. On the other hand, those who defend the status quo loudly claim that a change would destroy people's choices. Should this argument not suffice to justify a double system? If after several years few car owners opt for one of the plans and if the administrative costs of the mixed system are high, the less popular system could be eliminated.

10. The members of the household would be determined by the registrant when he registers a car. That is, the registrant would be required when registering to name the people who for insurance purposes would be considered part of his or her household. Conflicting registrations could be handled by any appropriate rule of thumb.

11. Obviously, the pool would have to compensate a passenger or pedestrian who was a member of a household in which no one owned a car and who opted for the New York plan and was injured by a car whose owner had opted for tort liability. Again, the pool would be a subrogated plaintiff against the injuring party. 
(An alternative, even then, would be to put all the administrative costs of a mixed system on the small minority.) If, instead, a sizeable number of car owners chose each of the systems, the argument that substantial free choice would be destroyed by having only one approach would be compelling. In effect, a double system would have given strong evidence of its value.

Once the free choice system demonstrates its value, the possibility of granting further options could be considered. As previously noted, the New York plan in its present form would offer two options to the car owners: (1) to bear the burden of pain and suffering and to be free from liability to others for the same; and (2) to buy scheduled, non-compulsory first party insurance for pain and suffering, and still have no third party liability. ${ }^{12} \mathrm{~A}$ further option that might be added later would be (3) to retain the right to recover for pain and suffering under the tort liability system, but to be liable to third parties for pain and suffering. In other words, a car owner would be allowed to opt for first party coverage with respect to economic damages and to opt for tort recovery rights and tort liability coverage with respect to pain and suffering.

As more options are allowed, of course, the system becomes more complex and administrative costs correspondingly increase. The expense involved, for example, in maintaining the pool required to deal with mixed accidents would undoubtedly rise as the number of options increased. To add these burdens to the system initially would be unnecessary and unwise. There is strong support for each of the two basic approaches; it is enough for the present to allow car owners adequate free choice between them. Further complications of the free choice system should be postponed until there is general demand for more options.

It should be obvious that these comments are not intended to indicate precisely how a free choice system should be established. This proposal is not meant to be a guide for drafting a statute, let alone for a commentary on a statute. Anyone drafting a statute embodying a free choice approach would have to deal with a myriad of problems, ranging from the handling of commercial vehicles to the problem of drunken drivers. These, like the precise handling of pedestrians and passengers, are issues that deserve more detailed thought than these comments can give. The purpose here, however, is to indicate that the problems can be dealt with effectively and that, as a result of dealing with them, the insurance buyer will be given a degree of choice in deciding what compensation-system he wishes. This result is not only desirable in itself, but will provide real information as to what car owners, in fact, want.

12. See note 6 supra and accompanying text; see also STATE of New YoRk INSURANCE Departackt, Automobite Insurance . . . For Whose Benefit? 95-97 (1970). 